\title{
Alguns comentários sobre o uso das construções do tipo dry wall no Brasil
}

O Brasil é um país que tem herança na construção civil associada a Portugal com uso quase total de alvenaria, principalmente para a confecção de residências de pequeno e médio porte. Esse tipo de construção apresenta vários problemas associados ao desperdício de material, uso excessivo de água, planejamento e projeto muita vez inadequados, logo vai em desencontro com os ideais de sustentabilidade tão importante para a preservação do ambiente. Os modelos de construções a seco oferecem residências mais econômicas e sustentáveis, podendo ser usada para alterar os processos de construção para os processos de montagem que são mais rápidos e eficientes. Nesse artigo, discutiu-se sobre as vantagens e algumas desvantagens do uso dos sistemas de construção a seco, como o gesso acartonado, o steel frame e o wood frame, além de citar alguns possíveis motivos do atraso do uso abrangente dessas tecnologias no Brasil.

Palavras-chave: Construção civil; Construções a seco; Gesso acartonado; Construções com aço; Construções em madeira.

\section{Some comments about the use of the dry wall's constructions in Brazil}

Brazil is a country that has inheritance in the civil construction associated to Portugal with almost total use of masonry, mainly for the creation of small and medium sized residences. This type of construction presents several problems associated with the waste of material, excessive use of water, planning and design very inadequate, soon goes in disagreement with the ideals of sustainability so important for the preservation of the environment. Dry construction models offer more economical and sustainable homes, and can be used to change building processes to faster and more efficient assembly processes. This paper discusses the advantages and disadvantages of using dry construction systems, such as gypsum, steel frame and wood frame, and to cite some possible reasons for the delay in the wide use of these technologies in Brazil.

Keywords: Civil construction; Dry wall constructions; Gypsum plaster; Steel frame; Wood frame.

Topic: Engenharia de Construção Civil

Reviewed anonymously in the process of blind peer.
Received: 16/01/2018

Approved: 22/04/2018

Tales Alexandre Aversi-Ferreira

Universidade Federal de Alfenas, Brasil

http://lattes.cnpq.br/1101341437463729

aversiferreira@gmail.com

\section{Referencing this:}

AVERSI-FERREIRA, T. A.. Alguns comentários sobre o uso das construções do tipo dry wall no Brasil. Engineering Sciences, v.6, n.1, p.21-31, 2018. DOI: http://doi.org/10.6008/CBPC23183055.2018.001.0003 


\section{INTRODUÇÃO}

Apesar da tecnologia na Construção de Civil estar sempre passando por inovações (COSTA et al., 2015), pelo menos para a grande maioria dos casos, as construções de pequeno e médio porte, no Brasil, são baseadas, de modo um tanto conservador, nas estruturas de alvenaria convencional (GOMES et al., 2013; LABUTO, 2014), com grande desperdício de materiais (VIEIRA, 2006), fazendo parte de um sistema ultrapassado em relação aos Estados Unidos, Canadá, Europa onde a tecnologia drywall é bastante utilizada como substituta à alvenaria (NUNES, 2015). A alvenaria no Brasil é uma herança portuguesa, pois em Portugal a madeira não era abundante e os engenheiros se especializaram em trabalhos de concreto (LAI, 2016).

O termo drywall, de origem inglesa, significa 'parede seca' (MORATO JUNIOR, 2008), em tradução livre, e designa uma tecnologia desenvolvida por Augustine Sackett e Fred L. Kane em 1894 para o uso de placas de gesso acartonado (WOJEWODA et al., 2010), que, no entanto, somente começou a ser usada para construção civil por volta de 1940, e, atualmente é uma alternativa para os métodos de construção a seco para vedações verticais leves, chamadas de divisórias internas (SABBATINI, 1998).

Essa tecnologia, o uso de gesso acartonado, apesar de ter começado a ser usada no Brasil na década de 1990 (SABBATINI, 1998), e difundida em maior escala no século XXI (LABUTO, 2014), está em constante crescimento, principalmente pelo aumento da oferta, pelas vantagens oferecidas em relação à alvenaria (COSTA et al., 2015), e pela mudança de perfil de obras do tipo construção para o tipo montagem (FREITAS et al., 2006), não obstante, suas características não atenderem os requisitos estruturais para vedações externas (BAUER, 2012). Essa demora para ser utilizada no Brasil parece ter gerado uma certa insegurança aos consumidores e engenheiros em usar os produtos de drywall (MITIDIERI, 2000). Inclusive na área acadêmica, ainda são poucas as produções científicas nacionais sobre a tecnologia drywall (CAMPOS, 2014).

Pode-se citar que o atraso no uso de drywall e sua expansão, no Brasil, também é dificultada por um aspecto cultural, pois as inovações hodiernas levam em conta a economia e a sustentabilidade, fatores essenciais para a sociedade moderna e que visam preservar o ambiente e dar mais conforto ao ser humano, e esse tipo de comportamento não é muito difundido em países em desenvolvimento que necessitam crescer sem destruir o ambiente (BOMFIM, 2010).

Na construção civil, a sustentabilidade passa pelo processo de diminuição dos resíduos produzidos, cuidados com o ambiente, evitar desperdício de água e material, cumprir os prazos de construção (o que diminui resíduos, consumo de água) (VIEIRA, 2006), entre outros, dependendo do tipo de obra e local onde ela está sendo realizada. A construção civil é um dos setores que gera grande quantidade de resíduos, com descarte destes, na maioria das vezes, irregular, tornando essa indústria em um dos maiores alvos da sustentabilidade (ZAPARTE, 2014).

O sistema drywall, de modo geral, é uma tecnologia de construção civil com material pré-fabricado, montado sem a necessidade do uso de água como insumo (NUNES, 2015), é um sistema pré-fabricado para edificações internas, forros, revestimentos e paredes não estruturais (divisórias) para ambientes úmidos ou secos para compartimentação de ambientes em casas e edifícios (MORATO JUNIOR, 2008; NUNES, 2015), no 
entanto, também, pode ser usado de modo estrutural como o caso da tecnologia light steel frame (LSF) que pode distribuir cargas e resistir ao efeito eólico (CARDOSO et al., 2016), o que também ocorre com a tecnologia woodframe.

A tecnologia de drywall vem em encontro com a necessidade premente de maior produtividade, redução de custos e prazos, qualidade do produto e menos impacto ambiental na construção civil (CARDOSO et al.; BARROS, 2016), podendo somar a esses fatores com competitividade acentuada desde a década de 1990 (GOMES et al., 2013), sendo uma das opções para inovação e soluções técnicas com bons desempenhos a alto custo-benefício, viabilidade de cálculos permitindo maior exatidão na quantidade de material a ser aplicado com menor tempo de execução e redução de preço (PEDROSO et al., 2014)..

Esse processo do uso da tecnologia drywall que está se iniciando no Brasil, ocorreu na Europa pósguerra onde a necessidade de reconstrução das cidades destruídas gerou a industrialização da construção civil, exigindo qualidade e rapidez, portanto, eficiência e ainda, padronização das construções (FERREIRA, 2014), algo parecido ao que ocorreu no desbravamento do oeste americano, em que a escassez de madeira levou à utilização do aço nas construções (CAMPOS, 2014).

Essa industrialização caracterizada na construção como o emprego racional e mecanizado de materiais, transporte e técnicas para gerar maior produtividade (BRUNA, 1976) não está bastante difundida no Brasil (FARIA, 2008; CAMPOS, 2014; FERREIRA, 2014), como se poderia desejar, mas parece estar em crescimento (FREITAS et al., 2006; GOMES et al., 2013). De fato, uma das alternativas para a industrialização da construção civil no Brasil é o uso do aço (SANTIAGO, 2012), material em que o país é um dos maiores produtores do Mundo.

A industrialização da construção civil pode conduzir, quando bem aplicado, à maior agilidade no canteiro de obras, diminuição da diversidade de materiais, diminuição acentuada de resíduos (CAMPOS, 2014), como citado acima, considerando esse caminho, não seria a metodologia drywall, hipoteticamente, mais viável para uma construção mais rápida e barata no Brasil?

Com o objetivo de discutir as vantagens e desvantagens do uso da tecnologia drywall no processo de industrialização da construção civil brasileira, nesse trabalho, serão analisados alguns dos sistemas drywall como o uso de gesso acartonado para paredes verticais, steel frame e wood frame e confeccionados comentários sobre as expensas financeiras, o tempo de construção e as vantagens em termos de sustentabilidade.

\section{METODOLOGIA}

Foram feitas buscas nos sistemas em bases eltronicas: Scielo, CAPES periódicos, Open Journal System e Google. Os descritores usados foram Dry Wall, Gesso Acartonado ou Gypsum plaster, Steel Frame ou Construções em Aço, Woodframe ou Construçoes em Madeira. O critério de inclusão foi dado para o uso dos materiais de construção no Brasil e como foram encontrados poucos artigos a respeito do tema, foram citadas muitas dissertações, teses e livros. A exclusão dos artigos levou em conta a repetição do tema nos documentos. 


\section{DISCUSSÃO TÉORICA}

\section{Gesso acartonado}

As vedações verticais são construídas via chapas de aço galvanizado e placas de gesso acartonado de alta resistência mecânica e acústica com espessura aproximada de $9 \mathrm{~cm}$ (BERNARDI, 2014). Teve início de uso por volta de 1920 nos Estados Unidos para fechamento interno e há cerca de 70 anos na Europa, locais onde o gesso acartonado está consolidado na construção civil, no entanto, apesar de estar crescendo o uso dessa tecnologia no Brasil, ainda é incipiente (NUNES, 2015), apesar das muitas vantagens oferecidas pelo sistema como substituto às paredes de vedação interna. Assim como outros de sistemas dry wall, o mercado não parece estar preparado para consolidação dessa tecnologia, principalmente pela falta de componentes e mão de obra qualificada (CEOTTO et al., 2006).

Não obstante, as citadas vantagens no uso das vedações verticais em gesso acartonado em relação à alvenaria, é preciso somar a rápida execução devido ao material ser pré-fabricado e de fácil transporte dentro da obra (SILVA, 2003; VIEIRA, 2006). O modo de construção pré-fabricado, evita desperdícios devido ao modo que os perfis são levados à obra, favorecendo a estocagem, e a montagem não gera entulho e desperdícios, e diminui ou quase anula o retrabalho, é versátil e flexível (VIEIRA, 2006). A pequena espessura da parede aumenta a área útil da construção em cerca de $4 \%$ em áreas construídas maiores que $10 \mathrm{~m}^{2}$ (SILVA, 2003).

O gesso gera alívio das estruturas em termos de carga com uma diminuição de cerca de $20 \%$ do peso em relação à alvenaria (SILVA, 2003), o que acarreta em menor gasto com argamassa de fundação, permitindo fundações mais rasas, portanto, mais baratas. A parte econômica é também evidentemente diminuída na redução da mão de obra tanto em termos de tempo de trabalho como da quantidade de operários, gerando menos gastos e diminuindo a quantidade horas/homem trabalhadas o que diminui, também, o risco de acidentes de trabalho. Outra vantagem do gesso acartonado, por ser oco, permite o alojamento de sistemas prediais com possíveis modificações futuras sem necessidade de rasgos, pois os espaços livres permitem a alocação de tubulações e eletrodutos (CEOTTO et al., 2005).

O sistema apresenta bom desempenho estrutural ao resistir aos esforços de solicitações verticais e horizontais, inclusive eólicas (CAMPOS, 2006), atendendo bem aos ensaios realizados segundo as especificações da NBR 15758 (MARTINS FILHO, 2010). Em relação ao conforto térmico e acústico, por possuir uma camada de ar na parede oca, o gesso acartonado se destaca pelo ótimo isolamento que ainda pode ser melhorado se ocorrer preenchimento com material absorvente (GROTRA, 2009), como lã de vidro reconhecida como um ótimo isolante térmico e acústico (CATAl et al., 2006), a ponto de atender às exigências na separação de salas de cinema (NUNES, 2015).

O gesso acartonado, devido a fatores como o preenchimento com componentes isolantes como a lã de vidro e a possibilidade de uso de chapas resistentes ao fogo além do gesso não ser um bom combustível fazem dessa tecnologia bastante resistente a incêndios (NUNES, 2015), no entanto, é aconselhável, e mesmo preciso, o uso de dispositivo corta fogo (CAMPOS, 2006). As desvantagens do uso de gesso acartonado, assim 
como ocorre com os casos de outras tecnologias dry wall, no Brasil, estão associadas à falta de mão de obra qualificada, a falta de planejamento adequado na construção (NUNES, 2015), a pouca resistência do material que sofre patologia se um leigo for usar pregos na parede, a falta de material adequado para a execução e acabamento (CEOTTO, 2010). Acrescenta-se a falta de preparação dos profissionais da construção civil em usar as novas tecnologias e da educação em engenharia, em relação a falta das disciplinas de construções sustentáveis nos currículos das faculdades de formação de engenheiros.

\section{Steel frame}

O aço é um material versátil com bom desempenho técnico e adaptável às várias condições que tem substituído muitos materiais nos setores industriais, inclusive na construção civil (SOUZA, 2014; GOMES et al., 2013), nesse caso, como aço galvanizado chamado de LSF ou estrutura leve de aço, faz parte do sistema de Construção Energitérmica Sustentável (CES) (PEDROSO et al., 2014).

Essa tecnologia é comumente usada nos Estados Unidos, Inglaterra, Canadá, Japão, Espanha (FERREIRA, 2014) além de Nova Zelândia e Austrália (PEDROSO et al., 2014). Nos Estados Unidos a madeira era a preferência para construções, mas que foi parcialmente substituída pelo steel frame devido à diminuição da oferta e consequente aumento dos preços (FERREIRA, 2014) e no Japão a expansão ocorreu

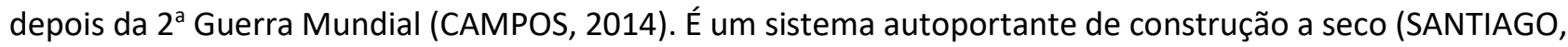
2012) que aumenta a velocidade do processo construtivo (RODRIGUES, 2012), é completo e de alta racionalidade que pode substituir a construção de alvenaria convencional (MANZIONE, 2004), interna e externamente.

No Brasil, a tecnologia steel frame foi trazida para casas de alto padrão, no entanto, já é utilizada em escala por algumas empresas como Ipiranga e McDonald's, em ambos os casos com objetivo de acelerar as construções dos pontos de venda e adequação à sustentabilidade (CAMPOS, 2014). A tecnologia steel frame se enquadra no processo de sustentabilidade prezado e em início de consolidação no Brasil (GOMES et al., 2013), com início em 1998, mas ainda é pouco difundido (CAMPOS, 2014; SOUZA, 2014). Ela pode substituir tijolos, madeiras, concreto com vantagens qualitativas e econômicas em processo mais industrializado, já que as chapas de aço têm espessura reduzida permitindo, entre outros, maior rapidez na execução da obra, redução do peso da construção, menor desperdício e as chapas são flexíveis, o que facilita o acabamento (PEDROSO et al., 2014).

O LSF é formado por perfis de aço galvanizado construídos a frio ou placas de fechamento para fazerem parte de estruturas ou outros propósitos (SANTIAGO, 2012; CAMPOS, 2014; SOUZA, 2014), com uma concepção racional. Os painéis de LSF podem funcionar estruturalmente como paredes, que associados aos elementos de vedação apresentam idênticas funções às das paredes de alvenaria (SANTIAGO et al., 2012).

De um modo geral, as vantagens das construções em steel frame estão associados à sustentabilidade em relação ao consumo de água (SANTIAGO, 2012; SOUZA, 2014) e diminuição de concreto, permite construção durante a chuva, gerando economia de tempo (SANTIAGO, 2012) e seu custo chega a ser $30 \%$ inferior a uma obra de mesmo porte em alvenaria comum (PEDROSO et al., 2014), apesar de que alguns 
autores citam a necessidade de novos estudos para verificar viabilidade econômica desse sistema na realidade brasileira (GOMES et al., 2013).

A leveza do aço galvanizado (SANTIAGO, 2012) é também uma vantagem, pois diminui a compressão sobre as fundações (GOMES et al., 2013; CAMPOS, 2014) e melhora a segurança da obra, não permite a propagação do fogo, não sofre ataque de cupins e resiste à corrosão devido ao revestimento com zinco (PEDROSO et al., 2014) e pode ser montada na construtora e levada a obra, ou ser montada nela.

As fundações para construções de até 2 andares com LSF podem ser rasas do tipo radier ou sapatas corridas (CAMPOS, 2014) que usam menos concreto e também distribui de modo mais uniforme o peso da construção. O tempo de construção chega a ser de $33 \%$ menor que uma obra comum de $100 \mathrm{~m}^{2}$, que pode ser finalizada em cerca de 30 dias, o que gera menor probabilidade de riscos de acidentes de trabalho (PEDROSO et al., 2014).

O sistema apresenta bom desempenho acústico e térmico devido às propriedades do material de revestimento como lã, vidro ou poliéster. Os custos com gasto de energia elétrica em função de aquecimento ou refrigeração é menor, pois a obra, como um todo, possui maior calor específico que a alvenaria, mantendo a temperatura interna por mais tempo (PEDROSO et al., 2014).

Apresenta baixo custo de manutenção pela facilidade de intervenção no sistema, com pouco barulho e sujeira, além de que o aço pode ser reaproveitado várias vezes (PEDROSO et al., 2014). Por ser um produto padronizado, apresenta rigoroso controle de qualidade e demonstrada resistência, durabilidade e longevidade da estrutura (SANTIAGO, 2012). As desvantagens ligadas ao LSF estão, também, associadas à leveza do material, pois restringe o número de andares, que não pode ser maior que cinco, e devido ao material de vedação, ocorrem muitos danos nas paredes, inclusive para pendurar objetos pesados (PEDROSO et al., 2014).

No caso do Brasil, uma desvantagem está associada à falta de mão de obra especializada construção e manutenção da obra (CAMPOS, 2014; PEDROSO et al., 2014), no caso da construção a falta de mão de obra qualificada pode gerar falhas de montagem do sistema (CAMPOS, 2014). Outro ponto negativo é a falta de aceitação dessa tecnologia na construção de residências, pois cresce mais para construções comerciais, o que parece fazer parte de um problema cultural (CAMPOS, 2014), tanto da população em geral quanto dos engenheiros e arquitetos que conhecem pouco sobre o sistema, muito pela falta de disciplinas específicas sobre o assunto nas faculdades.

As vantagens parecem superar as desvantagens a ponto de a Caixa Econômica Federal ter incentivado a construção LSF e tendo lançado as diretrizes para esse tipo de tecnologia para financiamento de habitações (CAIXA ECONOMICA FEDERAL, 2003). As especificações que versam de maneira mais ou menos direta sobre a tecnologia LSF estão nas normas ABNT NBR 15575/2013 sobre edifícios habitacionais de até cinco pavimentos; a NBR 14762/2010 sobre o dimensionamento de estruturas de aço; a NBR 7008/2003 sobre chapas e bobinas de aço revestidas com zinco ou com liga zinco-ferro pelo processo contínuo de imersão a quente; a NBR 7400/2009 sobre galvanização de produtos de aço ou ferro fundido por imersão a quente; a NBR 15253/2005 sobre a camada mínima de revestimento do aço. 


\section{Wood frame}

A madeira parece ser o mais antigo material de construção devido à sua disponibilidade na natureza (MOLINA et al., 2010; PFEIL et al., 2003), e talvez devido à relativamente fácil e rápida manipulação. Apresenta uma alta relação resistência/peso se comparada a outros materiais (PFEIL et al., 2003). De um modo geral, ao contrário do senso comum (CALIL JUNIOR et al., 2010), a construção em madeira exige material sustentável, renovável com produção não poluente e com baixo custo energético, aspectos que o reflorestamento fornece (ZAPARTE, 2014).

Levando em consideração a citada necessidade da sustentabilidade na construção civil, além do steel frame, aparece a alternativa do wood frame, um sistema construtivo industrializado, energitérmico (ZAPARTE, 2014) durável, feito em perfil de madeira reflorestada tratada, podendo formar painéis de pisos, paredes, telhados de modo combinado ou com revestimento de outros materiais, gerando maior conforto acústico e térmico (MOLINA et al., 2010; VASQUES et al., 2014), muito utilizado nos Estados Unidos, chegando a 95\% das residências construídas, onde foi inventada após a colonização europeia por volta de 1833 (ZAPARTE, 2014). É importante ressaltar que quando se usa o termo wood frame, ele se refere ao uso exclusivo de madeira de reflorestamento (MOLINA et al., 2010).

As paredes são painéis de madeira (umidade $<19 \%$ ) preenchidas com material isolante, passando por tratamento impermeabilizante e revestidas com placa cimentícia no lado externo e placas de gesso no lado interno (ZAPARTE, 2014). As placas de madeira são construídas na indústria e montadas no local da obra, apresentam montantes na estrutura para a ligação dos eixos verticais, com vergas nos membros horizontais em casos de aberturas (ZAPARTE, 2014). As ligações dos elementos estruturais devem ser feitas com parafusos galvanizados e pregos do tipo ardox (CALIL JUNIOR et al., 2010).

No Brasil, o uso da tecnologia wood frame, parece ter iniciado há cerca de 13 anos, atraso considerável que parece ser devido, também, às questões culturais (ZAPARTE, 2014), como a crença em ser essa uma construção frágil e sujeita a rápido desgaste (PFEIL et al., 2003). Ainda não existem normas específicas para as construções do tipo wood frame no país, então aconselha-se a utilização da norma Europeia (EUROCODE 5) (ZAPARTE, 2014), mas para o dimensionamento das placas de madeira pode-se usar a NBR 7190; 1997 e verificar outras recomendações em livros (para maiores detalhes ver os estudos de Calil Junior et al., 2003). Algumas empresas brasileiras começaram a realizar testes com as construções wood frame, sendo que a Construtora Roberto Ferreira executou junto com o grupo i-Verde um projeto com 280 habitações em Pelotas/RS, no ano de 2012 (ZAPARTE, 2014).

A economia ocorreu pela rapidez maior do projeto em relação à alvenaria, apesar do custo da madeira ter sido 5\% maior (ZAPARTE, 2014), portanto, economia na mão de obra, somando os benefícios de sustentabilidade, menor risco de acidentes em função do tempo horas-homem trabalhadas e, também, em relação à racionalização dos materiais gerando de menos resíduos (VASQUES et al., 2014; ZAPARTE, 2014).

De maneira geral, as vantagens da tecnologia wood frame são similares às citadas para o steel frame em relação à alternativa de sustentabilidade (VASQUES et al., 2014) e outros, no entanto, parece apresentar 
um melhor isolamento térmico e acústico, diminuindo o gasto de energia elétrica (ZAPARTE, 2014), de fato, absorve 40 vezes menos calor do que a alvenaria (MOLINA et al., 2010).

A tecnologia atende os níveis de segurança exigidos pelas normas técnicas contra incêndio e som (ZAPARTE, 2014) e são mais econômicas para construções residenciais de até 2 pavimentos (STRICKLIN et al., 1996) e pode ser adaptada a diferentes climas e regiões, além de apresentar a estabilidade no preço da matéria prima (VASQUES et al., 2014). Quanto às fundações, devido à leveza da estrutura, ocorrerá diminuição dos custos, pois a construção wood frame permite uma distribuição equitativa das cargas nas paredes, tornando a estrutura hiperstática, com menor risco de ruptura, sem a necessidade de pilares e vigas (ZAPARTE, 2014), de fato, na alvenaria o preço da fundação para uma casa de $74 \mathrm{~m}^{2}$ corresponde a cerca de $15 \%$ dos custos, sendo $10 \%$ mais barato para a fundação se ela for construída pelo método wood frame, com um prazo de execução de 8 para 2 meses, respectivamente (VASQUES et al., 2014).

No Canadá, as fundações são de três tipos, o basement wall (estrutura subterrânea de paredes), crawl space e radier, no entanto, com a necessidade de uma certa adequação para o Brasil (para maior detalhe ver a pesquisa de Zaparte, 2014). Entre as principais desvantagens do uso da tecnologia wood frame no Brasil, está o desconhecimento do uso adequado do método, i.e., a falta de mão de obra especializada, a altura das edificações que não devem passar cinco pavimentos, baixa oferta de ferramentas específicas e resistência do mercado às mudanças (VASQUES et al., 2014).

\section{CONCLUSÕES}

Uma casa ideal deve ser confortável, segura, resistente a desastres, durável, eficiente e, sobretudo, sustentável (POWELL et al., 2008), mas, essa é uma afirmação difícil de ser efetivada em um país como o Brasil onde a quantidade de residências é insuficiente para a população e onde os padrões de construção civil estão anos atrasados em relação aos países desenvolvidos (GOMES et al., 2013; LABUTO, 2014).

No entanto, para efetivar a construção de casas ideais, a construção civil no Brasil deve dar opções de novas tecnologias aos clientes, e uma dessas tecnologias é a do dry wall, tanto para vedações verticais como para construção estruturais. As tecnologias do tipo dry wall comentadas nesse trabalho mostraram vantagens em relação à tradicional alvenaria, não obstante as vantagens que também existem na construção conservadora, no entanto, os novos métodos encontram resistências para se tornarem usuais, ou até mesmo opcionais

Em termos de origem dos problemas, citam-se a falta de trabalhos acadêmico-científicos na área (nesse trabalho foram usados muitos textos de referência oriundos de dissertações e teses) e desinteresse dos engenheiros (MOLINA et al., 2010) em tentar usar métodos diferentes do tradicional na construção (ZAPARTE, 2014), além da falta de disciplinas voltadas para a construção do tipo dry wall nas faculdades de engenharia.

É preciso elucidar que a falta de trabalhos científicos e falta de/ou restrita especialização na área, diminui a qualificação da mão de obra, pois não há instrutores adequados para coordenar os trabalhos construtivos. Sobre as técnicas de dry wall, no Brasil, são encontradas não muitas monografias, dissertações 
de mestrado, ainda menos teses e bem menos artigos em revistas especializadas, por outro lado, pode-se acrescentar que a construção de casas usando a tecnologia dry wall, se não forem bem planejadas e montadas, gerará maior insegurança na população quanto à aceitação da tecnologia, pois rapidamente demonstrará problemas.

Um dos problemas associado a isso é que no processo de construção de alvenaria, o inadequado projeto e planejamento pode ser camuflado pelo excesso de material como ferragem e concreto, o que torna a obra quase sempre mais cara do que o planejado, enquanto que na montagem pré-fabricada isso não é possível, podendo gerar consequências desagradáveis ao consumidor. Interessantemente, mesmo para um país com deficiência financeira da população, os sistemas sustentáveis dry wall são ainda pouco aceitos, o que parece um contrassenso, pois para o caso wood frame, a economia chega a 5\% na obra e é ainda mais barata no caso steel frame, que chega a cerca de $30 \%$.

Portanto, é forçoso concluir que o uso de tecnologias que ofereçam vantagens sustentáveis e econômicas deve passar por uma melhora no entendimento dos processos, com a implantação de disciplinas específicas sobre dry wall e construções modernas nos cursos com a devida preparação dos professores e aumentar o número de pós-graduações voltadas para as tecnologias novas com incentivo para os egressos dos cursos de engenharia e arquitetura realizarem a especialização na área. Esse parece ser o caminho mais lógico, pois os engenheiros e arquitetos são os maiores formadores de opinião na construção civil por estarem em contato direto $\mathrm{cm}$ os clientes. Nesse caso, esses profissionais podem mudar as concepções vigentes sobre as novas tecnologias.

Somente os valores da sustentabilidade associados à economia de água e energia, que se inserem dentro do nexo da sustentabilidade (JACOBI et al., 2017), já deveria ter gerado um processo de expansão das tecnologias de construção a seco, no entanto, somam-se a esses valores a necessidade de casas economicamente mais viáveis para a população, mais confortáveis e modernas em termos de manutenção, fatores oferecidos pelo uso do LSF, wood frame e gesso acartonado para vedações.

As informações aqui trazidas devem ser consideradas preliminares, pois discussões e estudos devem ser realizados para comparar mais especificamente os preços e a viabilidade das construções em cada região do país. De fato, em alguns lugares com mais madeira à disposição o wood frame poderá ser mais adequado do que o steel frame, pois comparações entre esses métodos não foram encontrados, ainda, na literatura para as condições do Brasil.

\section{REFERÊNCIAS}

BAUER, L. A. F.. Materiais de construção. 5 ed. Rio de Janeiro: LTC, 2012

BERNARDI, V. B.. Análise do Método Construtivo de Vedação Vertical Interna em Drywall em Comparação com a Alvenaria. Lages, 2014.

BOMFIM, A. M.. O sub(desenvolvimento) insustentável: a questão ambiental nos países periféricos latino-americanos. Trabalho Necessário, v.8, n.10, p.1-18. 2010.
BRUNA, P.. Arquitetura, industrialização e desenvolvimento. São Paulo: EDUSP/Perspectiva, 1976.

CAIXA ECONÔMICA FEDERAL. Sistema Construtivos Utilizando Perfis Estruturais Formados a Frio de Aço Revestido (Steel Framing): Requisitos e Condições Mínimas para Financiamento pela Caixa. Brasília: CAIXA, 2003.

CALIL JUNIOR, C.; LAHR, F. A. R.; DIAS, A. A.. Dimensionamento de elementos estruturais de madeira. Barueri: Manole, 2003. 
CALIL JUNIOR, C.; MOLINA, J. C.. Cobertura em estruturas de madeira: exemplos de cálculo. São Paulo: PINI, 2010.

CAMPOS, P. F.. Light Steel Framing: Uso em construções habitacionais empregando a modelagem virtual como processo e projeto e planejamento. Dissertação (Mestrado) - Universidade de São Paulo, São Paulo, 2014.

CARDOSO, S. S.; BARROS, M. M. B.. Especificação de perfis para drywall e light steel framing. In: CONGRESSO LATINOAMERICANO DA CONSTRUÇÃO METÁLICA. Anais. São Paulo, 2016.

CATAI, R. E.; PENTEADO, A. P.; DALBELLO, P. F.. Materiais, Técnicas e Processos para Isolamento Acústico. In: CONGRESSO BRASILEIRO DE ENGENHARIA E CIÊNCIA DOS MATERIAIS, 17. Anais. Foz do Iguaçu, 2006.

CEOTTO, L. H.; BANKUK, R. C.; NAKAKURA, E. H. Revestimentos de argamassas: boas práticas em projeto, execução e avaliação. Porto Alegre: ANTAC, 2005.

COSTA, A. T.; NASCIMENTO, F. B. C.. Uso de gesso acartonado em vedações internas. Cadernos de graduação. v.2, n.3, p.99-106, 2015.

FARIA, R.. Industrialização econômica. Revista TÉCHNE, n.136, 2008.

FERREIRA, A. S.. Estudo comparativo de sistemas construtivos industrializados: paredes de concreto, steel frame e wood frame. Monografia (Bacharelado) Universidade Federal de Santa Maria, Santa Maria, 2014.

FREITAS, A. M. S.; CRASTO, R. C. M.. Steel framing: arquitetura. Rio de Janeiro: IBS/CBCA, 2006.

GOMES, C. E. M.; VIVAN, A. L.; SICHIERI, E. P.; PALIARI, J. C.. Light steel frame na produção de moradias no Brasil. In: CONGRESSO DE CONSTRUÇÃO METÁLICA E MISTA, 9 \& CONGRESSO LUSO-BRASILEIRO DE CONSTRUÇÃO METÁLICA SUSTENTÁVEL, 1. Anais. Porto, 2013.

GROTRA, D. L.. Materiais e Técnicas Contemporâneas para Controle de Ruído Aéreo em Edificações de Escritórios: Subsídios para Especificações. Dissertação (Mestrado) Universidade de São Paulo, São Carlos, 2009.

JACOBI, P. R.; GIATTI, L. L.. Nexos para a sustentabilidade: a busca por uma nova racionalidade. Revista Ambiente \& Sociedade, São Paulo, v.20, n.2, p.1-6, 2017.

LABUTO, L. V.. Parede seca - sistema construtivo de fechamento de estrutura de drywall. Monografia (Bacharelado) - Universidade Federal de Minas Gerais, Belo Horizonte, 2014.

LAI, L.. Verificação do custo-benefício do sistema Drywall segundo a norma ABNT NBR 15575:2013. Monografia (Bacharelado) - Universidade Federal do Rio de Janeiro, Rio de Janeiro, 2016.

MANZIONE, L.. Projeto e Execução de Alvenaria Estrutural. São Paulo: O Nome da Rosa, 2004.
MARTINS FILHO, L. A.. Sistema Drywall atende à Norma de Desempenho. 2010.

MITIDIERI, C.. Drywall no Brasil: Reflexões Tecnológicas. 2000.

MOLINA, J. C.; CALIL JUNIOR, C.. Sistema construtivo em wood frame para casas de madeira. Semina: Ciências Exatas e Tecnológicas, Londrina, v.31, n.2, p.143-156, 2010.

MORATO JUNIOR, J. A.. Divisórias de Gesso Acartonado: Sua utilização na construção civil. Monografia (Bacharelado) Universidade Anhembi Morumbi, São Paulo, 2008.

NUNES, H. P.. Estudo da aplicação do Drywall em edificação vertical. Monografia (Bacharelado) - Universidade Tecnológica Federal do Paraná, Mourão, 2015.

PEDROSO, S. P.; FRANCO, G. A.; BASSO, G. L.; BOMBONATO, F. A.. Steel Frame na construção civil. In: ENCONTRO CULTURAL CIENTÍFICO INTERINSTITUCIONAL, 12. Anais. 2014.

PFEIL, W.; PFEIL, M.. Estruturas de Madeira. 6 ed. Rio de Janeiro: LTC, 2003.

POWELL, K. L.; TILOTTA, D. C.; MARTINSON, K. L. Assessment of research and technology transfer needs for wood-frame housing. Madison: USDA, 2008.

RODRIGUES, F. C.. Manual de Construção em Aço: Steel Framing: Engenharia. Rio de Janeiro: Instituto Brasileiro de Siderurgia/CBCA, 2012.

SABBATINI, F. H.. O processo de produção das vedações verticais leves de gesso acartonado. In: SEMINÁRIO TECNOLOGIA E GESTÃO NA PRODUÇÃO DE EDIFÍCIOS VEDAÇÕES VERTICAIS. Anais. São Paulo, 1998.

SANTIAGO, A. K.. Manual de Construção em Aço: Steel Framing: Arquitetura. Rio de Janeiro: Instituto aço Brasil/CBCA, 2012.

SANTIAGO, A. K.; FREITAS, A. M. S.; CRASTO, R. C. M. Manual de Construção em Aço - Steel Framing: Arquitetura. 2 ed. Rio de Janeiro: Instituto Aço Brasil/CBCA, 2012.

SILVA, M. M. A.. Diretrizes Para o Projeto de Alvenaria de Vedação. Dissertação (Mestrado) - Universidade de São Paulo, São Paulo, 2003.

SOUZA, E. L.. Construção Civil e Tecnologia: Estudo do Sistema Construtivo Light Steel Framing. Monografia (Bacharelado) - Universidade Federal de Minas Gerais, Belo Horizonte, 2014.

STRICKLIN, D. L.; SCHIFF, S. D.; ROSOWSKY, D. V.. Uplift Capacity of Light-Frame Wood Stud Walls. In: INTERNATIONAL WOOD ENGINEERING CONFERENCE. Anais. New Orleans, 1996.

VASQUES, C. C. P. C. F.; PIZZO, L. M. B.. Comparativo de sistemas construtivos, convencional e wood frame em residências unifamiliares. Cognitio. n.1, p. 1-17. 2014. 
VIEIRA, H. F.. Logística aplicada à Construção Civil: Como Melhorar o Fluxo de Produção nas Obras. São Paulo: Pini, 2006.

WOJEWODA, K; ROGALSKI, P.. Identification of materials used in Technology of Interior Drywall Systems. Varsóvia: Instytut Technology Eksploatacji, 2010.
ZAPARTE, T. A.. Estudo e adequação dos principais elementos do modelo canadense de construção em Wood Frame para o Brasil. Monografia (Bacharelado) Universidade Tecnológica Federal do Paraná, Pato Branco, 2014.

A CBPC - Companhia Brasileira de Produção Científica (CNPJ: 11.221.422/0001-03) detém os direitos materiais desta publicação. Os direitos referem-se à publicação do trabalho em qualquer parte do mundo, incluindo os direitos às renovações, expansões e disseminações da contribuição, bem como outros direitos subsidiários. Todos os trabalhos publicados eletronicamente poderão posteriormente ser publicados em coletâneas impressas sob coordenação da Sustenere Publishing, da Companhia Brasileira de Produção Científica e seus parceiros autorizados. Os (as) autores (as) preservam os direitos autorais, mas não têm permissão para a publicação da contribuição em outro meio, impresso ou digital, em português ou em tradução. 